ОПРЕДЕЛЕНИЕ ФТАЛАТОВ В МОЛОКЕ, МОЛОЧНЫХ ПРОДУКТАХ, ВОДЕ, СОКАХ И НАПИТКАХ МЕТОДОМ УЛЬТРАВЫСОКОЭФФЕКТИВНОЙ ЖИДКОСТНОЙ ХРОМАТОГРАФИИ/КВАДРУПОЛЬ-ВРЕМЯПРОЛЕТНОЙ МАСС-СПЕКТРОМЕТРИИ ВЫСОКОГО РАЗРЕШЕНИЯ

\author{
(c) Надежда Михайловна Авдеева'1, Василий Григорьевич Амелин1, 2 \\ 1 Федеральный центр охраны здоровья животных, г. Владимир, Россия; e-mail: nadezhda_m_avdeeva@mail.ru \\ 2 Владимирский государственный университет им. А. Г. и Н. Г. Столетовых, г. Владимир, Россия; \\ e-mail: amelinvg@mail.ru
}

Статья поступила 10 января 2018 г.

Повсеместное использование полиэтилентерефталатной упаковки (ПЭТ) на рынке продовольственных товаров является потенциальной угрозой для здоровья потребителей. В процессе изготовления данных полимерных материалов используются различные вещества, улучшающие свойства готовой упаковки: в частности, одними из таких добавок являются фрталаты. Поскольку их молекулы химически не присоединены к полимерным цепям, эти вещества могут легко переходить из пластиковой тары в продукты питания, напитки и воду во время упаковочных или производственных процессов. В целях установления возможности попадания этих опасных соединений в продукцию путем их миграции из полиэтилентерефталатной упаковки проведен мониторинг остаточных количеств семи эфиров фрталевой кислоты (диметилфталата, диэтилфталата, диаллилфталата, дибутилфталата, диизобутилфталата, диизооктилфталата, диизододецилфталата) в ряде пищевых продуктов и напитков. Целевые аналиты извлекали из образцов молока, молочной продукции, воды, соков и напитков с использованием ацетонитрила и высаливателей и определяли методом ультравысокоэффективной жидкостной хроматографии с тандемным квадруполь-времяпролетным масс-спектрометрическим детектором высокого разрешения. Содержание обнаруженных фрталатов в продуктах питания, приобретенных в супермаркетах, изменялось в широких пределах: наиболее высоким почти для каждой категории исследованных образцов оказалось содержание диизооктилфталата, этот же эфир фталевой кислоты был и самым распространенным, за ним следуют дибутилфталат, диизобутилфталат и диэтилфталат. Диапазон определяемых содержаний эфиров фрталевой кислоты составил 15 - 3000 нг/мл $\left(R^{2} \geq 0,99\right)$, пределы обнаружения - от 0,5 до 15 нг/мл. Относительное стандартное отклонение результатов анализа не превышало $15 \%$.

Ключевые слова: фрталаты; полиэтилентерефталатная упаковка; анализ пищевой продукции; ультравысокоэффективная жидкостная хроматография/времяпролетная масс-спектрометрия высокого разрешения.

\title{
DETERMINATION OF PHTHALATES IN MILK, DAIRY PRODUCTS, WATER, JUICES AND BEVERAGES USING ULTRAHIGH LIQUID PERFORMANCE CHROMATOGRAPHY/QUADRUPOLE TIME-OF-FLIGHT MASS SPECTROMETRY OF HIGH RESOLUTION
}

\section{(C) Nadezhda M. Avdeeva1 and Vasily G. Amelin1, 2}

1 Federal Center for Animal Health, Vladimir, Russia; e-mail: nadezhda_m_avdeeva@mail.ru

2 A. G. and N. G. Stoletov Vladimir State University, Vladimir, Russia; e-māil: amelinvg@mail.ru

The widespread use of polyethylene terephthalate packaging (PET) in the food market can be a threat to the health of people. In the process of manufacturing these polymeric materials, various substances are used that improve the properties of the finished package. In particular, phthalates are considered to be one of these dangerous pollutants because their molecules are not chemically attached to polymer chains, these substances can easily pass from plastic containers to food, beverages and water during packaging or production processes. The study was carried out by ultrahighperfomance liquid chroma- 
tography with a tandem quadrupole-time-of-flight mass spectrometric high-resolution detector. The concentrations of phthalates was varies widely in foodstuffs purchased in food market, diisooctyl phthalate has been found in the highest concentration in almost every category of specimens studied. The same phthalic acid ester proved to be the most common, followed by dibutyl phthalate, diisobutyl phthalate and diethyl phthalate. The ranges of detectable contents for phthalates were $15-3000 \mathrm{ng} / \mathrm{ml}$ $\left(R^{2} \geq 0,99\right)$. Limit of detection were from 0.5 to $15 \mathrm{ng} / \mathrm{ml}$. The relative standard deviation of the analysis results did not exceed $15 \%$.

Keywords: phthalates; polyethylene terephthalate packaging; food analysis; ultra-high-performance liquid chromatography/high-resolution time-of-flight mass spectrometry.

Фталаты (сложные эфиры фрталевой кислоты) используют как пластификаторы для повышения гибкости пластмасс и широко применяют в производстве, в том числе, при изготовлении пищевой упаковки. Благодаря своим свойствам, таким как термо- и фотостабильность, устойчивость к гидролизу в нейтральной среде, данные соединения могут накапливаться в окружающей среде [1]. Их миграция из пластиковой тары приводит к загрязнению пищевой продукции [2]. Воздействие фрталатов на здоровье человека еще не до конца изучено, однако считается, что данные соединения могут вызывать ряд серьезных заболеваний, в том числе, онкологических, а также бесплодие, болезни эндокринной системы и др. [3]. В РФ установлены предельно допустимые уровни содержания фрталатов из упаковочных материалов, контактирующих с пищевой продукцией (табл. 1).

При оценке содержания эфиров фрталевой кислоты в продуктах питания и напитках возникает ряд трудностей, обусловленных возможным попаданием этих соединений из окружающей среды в ходе анализа. Для снижения фоновой концентрации этих веществ стараются уменьшить объем растворителей для экстракции, при- меняют холостые пробы, проводят очистку используемых реактивов $[3,6]$.

Для контроля содержания данных веществ в пищевой продукции и напитках используют газовую хроматографию с пламенно-ионизационным (ГХ ПИД) [1] или масс-селективным детектированием (ГХ МС) [3, 6 - 11], а также высокоэффективную жидкостную хроматографию c масс-спектрометрическим детектированием (ВЭЖХ МС) [6, 12,13]. При пробоподготовке обычно используют жидкостно-жидкостную (ЖЖЭ) [3] и твердофазную экстракцию (ТФЭ) $[12,13]$. Недостатками этих техник извлечения аналитов являются трудоемкость, длительность процесса, использование больших объемов растворителей. Данную проблему решают такие методики пробоподготовки, как QuEChERS [10] и дисперсионная жидкостно-жидкостная микроэкстракция (ДЖЖМЭ) $[1,8,11]$, которые позволяют извлекать и концентрировать целевые аналиты.

Цель данной работы - разработка методики идентификации и определения эфиров фталевой кислоты в молоке, молочной продукции, напитках и соках методом ультравысокоэффективной жидкостной хроматографии с тандемным квадруполь-времяпролетным масс-спектрометрическим

Таблица 1. Основные характеристики эфиров фрталевой кислоты, определяемых методом УВЭЖХ-ВПМС

\begin{tabular}{|c|c|c|c|c|c|c|c|}
\hline \multirow[b]{2}{*}{ Аналит } & \multirow[b]{2}{*}{$\begin{array}{l}\text { Брутто- } \\
\text { формула }\end{array}$} & \multirow[b]{2}{*}{ Ион } & \multirow[b]{2}{*}{$t_{R}$, мин } & \multirow[b]{2}{*}{$\mathrm{m} / \mathrm{z}$} & \multirow{2}{*}{$\begin{array}{c}\text { ПДК, нг/мл } \\
\text { Вода } \\
\text { питьевая [4] }\end{array}$} & \multirow{2}{*}{$\begin{array}{c}\text { ДКМ*, нг/мл } \\
\text { Вода бутилиро- } \\
\text { ванная, молоко, } \\
\text { соки, напитки [5] }\end{array}$} & \multirow[b]{2}{*}{$\begin{array}{c}\text { ПО, } \\
\text { нг/мл }\end{array}$} \\
\hline & & & & & & & \\
\hline \multirow[t]{2}{*}{ Диметилфталат } & $\mathrm{C}_{10} \mathrm{H}_{10} \mathrm{O}_{4}$ & {$[\mathrm{M}+\mathrm{H}]^{+}$} & 4,02 & 195,0652 & 300 & - & 5 \\
\hline & & {$\left[\mathrm{M}-\mathrm{CH}_{3} \mathrm{O}\right]^{+}$} & & 163,0390 & & & 1 \\
\hline \multirow{2}{*}{ Диэтилфталат } & $\mathrm{C}_{12} \mathrm{H}_{14} \mathrm{O}_{4}$ & {$[\mathrm{M}+\mathrm{H}]^{+}$} & 4,57 & 223,0965 & 3000 & - & 1 \\
\hline & & & 5,58 & & & & 0,5 \\
\hline Диаллилфрталат & $\mathrm{C}_{14} \mathrm{H}_{14} \mathrm{O}_{4}$ & {$[\mathrm{M}+\mathrm{H}]^{+}$} & 4,81 & 247,0965 & —** & - & 15 \\
\hline Дибутилфрталат & $\mathrm{C}_{16} \mathrm{H}_{22} \mathrm{O}_{4}$ & {$[\mathrm{M}+\mathrm{H}]^{+}$} & 5,57 & 279,1591 & 200 & Не допускается & 0,05 \\
\hline Диизобутилфталат & $\mathrm{C}_{16} \mathrm{H}_{22} \mathrm{O}_{4}$ & {$[\mathrm{M}+\mathrm{H}]^{+}$} & 5,57 & 279,1591 & 200 & - & 0,05 \\
\hline Диизооктилфталат & $\mathrm{C}_{24} \mathrm{H}_{38} \mathrm{O}_{4}$ & {$[\mathrm{M}+\mathrm{H}]^{+}$} & 7,20 & 391,2843 & 1600 & - & 0,1 \\
\hline Диизододецилфталат & $\mathrm{C}_{28} \mathrm{H}_{46} \mathrm{O}_{4}$ & {$[\mathrm{M}+\mathrm{H}]^{+}$} & 7,32 & 447,3469 & - & 2000 & 15 \\
\hline
\end{tabular}

* Допустимые количества химических веществ, выделяющихся из материалов, контактирующих с пищевыми продуктами.

** Не установлены. 
детектором высокого разрешения и оценка миграции этих веществ из ПЭТ в продовольственные товары.

Anпаратура и реактивьл. Использовали ультравысокоэффективный жидкостной хроматографр UltiMate 3000 (Thermo Scientific, США) в сочетании с квадруполь-времяпролетным массспектрометрическим детектором maXis 4G и устройство для электрораспылительной ионизации ionBooster (Bruker Daltonics, Германия). Разделение проводили на колонке $30 \times 2,1 \mathrm{~mm}$ ACQUITY UPLC ${ }^{\circledR}$ BEN C18 с диаметром зернения 1,7 мкм (Waters, CША) в режиме градиентного элюирования.

Использовали стандартные образцы (Dr. Ehrenstorfer, Германия) с содержанием основного вещества - диизододецилового эфира фрталевой кислоты - не менее 99,5 \%; диизооктилового эфира фрталевой кислоты — не менее 99,4 \%; диаллилового эфира фрталевой кислоты - не менее $98 \%$; дибутилового эфира фрталевой кислоты не менее $99 \%$; диэтилового эфира фрталевой кислоты — не менее 99,5 \%; диизобутилового эфира фрталевой кислоты - не менее 99 \%; диметилового эфира фрталевой кислоты - не менее 99,5\%. Исходные растворы с концентрацией 1 мг/мл готовили растворением соответствующей навески в ацетонитриле. Хранили растворы при $-20{ }^{\circ} \mathrm{C}$ не более шести месяцев. Рабочие растворы готовили разбавлением исходных ацетонитрилом в день использования.

Использовали ацетонитрил (Scharlab S.L., Испания) 99,9\%; изопропиловый спирт для ВЭЖХ (Scharlab S.L., Испания); метанол PAACS-ISO (Panreac, EC); янтарную кислоту квалификации ч (МСД «КЕМИКАЛ», Россия); ЭДТА (этилендиаминтетраацетат натрия) $99 \%$ («ХИММЕД», Россия); сульфрат аммония хч (ЗАО «Химреактив», Россия); гексан $96 \%$ (Scharlab S.L., Иcпания); хлорид натрия хч («ХИММЕД», Россия).

Способъл приготовления образцьов. Для анализа использовали два варианта пробоподготовки.

А. В стеклянную центрифружную пробирку объемом 15 мл вносили 1,00 мл тщательно перемешанного образца, добавляли 2,0 мл ацетонитрила, 0,5 г NaCl, 40,0 мг ЭДТА и перемешивали в течение 5 мин, затем центрифугировали в течение 5 мин при 2700 мин $^{-1}$. Отбирали верхний ацетонитрильный слой в стеклянный флакон и упаривали досуха, к сухому остатку добавляли 50 мкл ацетонитрила и 950 мкл деионированной воды, перемешивали 5 мин и фильтровали через мембранный фильтр с диаметром пор 0,45 мкм (GHP ACRODISC 13, PALL, CШA) в микрофолакон для хроматографирования.
Б. В стеклянную центрифружную пробирку объемом 15 мл вносили навеску тщательно перемешанного образца объемом 1,00 мл, добавляли 12,0 мг янтарной кислоты, 40,0 мг ЭДТА, 2,0 мл деионированной воды, перемешивали в течение 5 мин, добавляли 2,0 мл ацетонитрила, 2,0 г сульфата аммония и перемешивали 5 мин, затем центрифугировали в течение 5 мин при 2700 мин $^{-1}$. Отбирали верхний ацетонитрильный слой в стеклянный фрлакон и упаривали досуха, к сухому остатку добавляли 50 мкл ацетонитрила и 950 мкл деионированной воды, перемешивали 5 мин и фильтровали через мембранный фрильтр (0,45 мкм) в микрофлакон для хроматографирования.

Идентификация и определение. Идентификацию фрталатов по полученным хроматограммам проводили с использованием программного продукта DataAnalysis-4.1, TargetAnalysis (Bruker Daltonics, Германия), составление картины изотопного распределения аналитов - с использованием IsotopePattern (Bruker Daltonics, Германия). Неизвестную концентрацию аналита в пробе рассчитывали методом стандартной добавки по фрормуле:

$$
c_{x}=c_{\text {доб }} /\left(\left[\left(S_{x+\text { доб }} / S_{x}\right)\right]-1\right),
$$

где $c_{\text {доб }}$ - концентрация добавки в пробе, нг/мл,

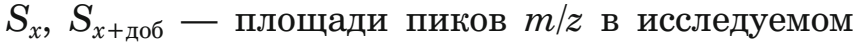
растворе и в растворе с добавкой аналита соответственно.

Оиенка матричного эффректа. Для оценки матричного эфрфекта (МЭ) использовали площади хроматографических пиков аналитов с концентрацией 100 нг/мл, полученные при анализе экстракта молока, не содержащего определяемых соединений, и деионированной воды. Расчет МЭ проводили по формуле:

$$
\mathrm{M} \ni=\left(S / S_{0}-1\right) \cdot 100 \%
$$

где $S, S_{0}$ - площади хроматографических пиков аналитов, полученные для экстракта молока и деионированной воды соответственно.

Условия хроматографического разделения $и$ детектирования. Подвижная фраза состояла из 0,1 \%-ного водного раствора муравьиной кислоты (A) и 0,1\%-ного раствора муравьиной кислоты в ацетонитриле (Б). Осуществляли градиентное элюирование: 0 мин - $5 \%$ Б, 0,5 мин - $5 \%$ Б, 2 мин - $50 \%$ Б, 5 мин - $100 \%$ Б, 6 мин - $5 \%$ Б, 10 мин - $5 \%$ Б. Скорость потока подвижной фазы составляла 0,4 мл/мин, оптимальная температура хроматографической колонки - $50{ }^{\circ} \mathrm{C}$, объем вводимой пробы - 50 мкл, температура термостата автосамплера $-10{ }^{\circ} \mathrm{C}$. 


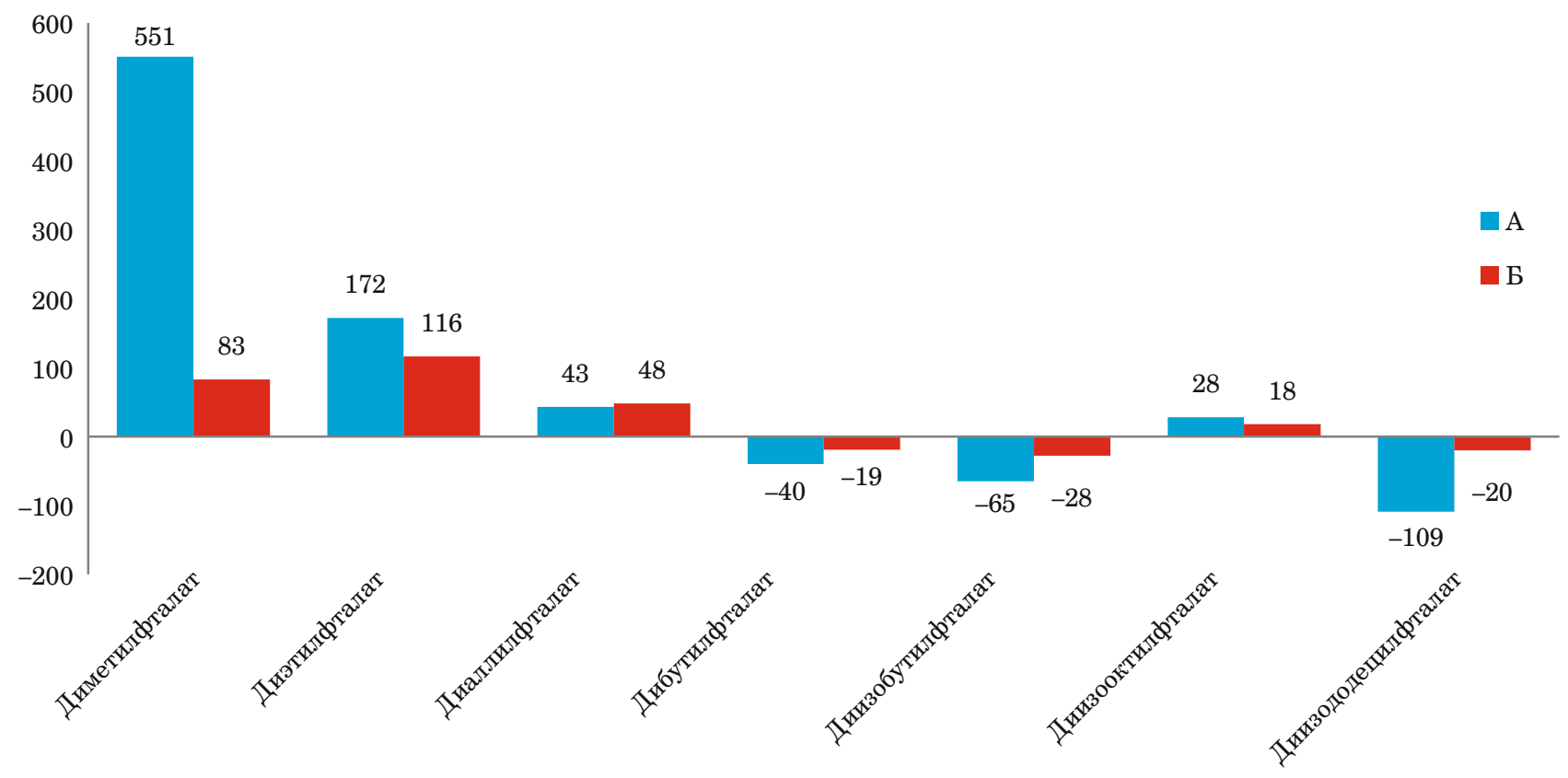

Рис. 1. Матричный эффект (\%) для фрталатов при различных способах пробоподготовки (А, Б)

Для электрораспылительной ионизации использовали устройство ionBooster при следующих установленных оптимальных значениях параметров: напряжение на щите капилляра $400 \mathrm{~B}$, на капилляре $-1000 \mathrm{~B}$; давление газараспылителя (азота) - 4,76 атм; поток газа-осушителя (азота) - 6 л/мин, его температура $200{ }^{\circ} \mathrm{C}$; поток газа-испарителя (азота) -250 л/ч, его температура $-250{ }^{\circ} \mathrm{C}$.

Регистрировали массы ионов в диапазоне 100 - 1100 Да. При регистрации положительных ионов для калибровки использовали $10 \mathrm{mM}$ раствор формиата натрия в смеси вода - изопропанол (1:1) в интервале хроматографирования 9,5 - 10 мин.

Идентификация. Эфиры фталевой кислоты в условиях электрораспылительной ионизации образуют протонированные формы $[\mathrm{M}+\mathrm{H}]^{+}$(см. табл. 1). Идентификацию остаточных количеств фрталатов в воде и пищевой продукции проводили с использованием программного продукта TargetAnalysis-1.3. Идентификационными параметрами служили времена удерживания $( \pm 0,2$ мин), точность массы моноизотопа $(\mathrm{m} / z$, $\pm 5 \mathrm{ppm})$ и совпадение картины изотопного распределения (mSigma < 20). Погрешность в определении масс ионов не превышала $\pm 3 \mathrm{ppm}$ $(n=3)$, разрешающая способность - более 30000 .

Оптимизаиия этапа пробоподготовки. Вторичное загрязнение проб фрталатами из окружающей среды затрудняет оценку их реального содержания, поэтому некоторые авторы [4] предлагают в целях снижения фоновых концентраций,
Рис. 2. Маркировка пластиковой упаковки, изготовленной из ПЭТ

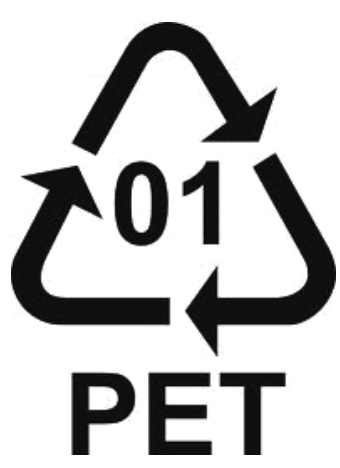

в частности, уменьшить до минимально возможных объемы растворителей и число операций во время приготовления образцов. В настоящей работе для экстракции использовали упрощенный вариант метода пробоподготовки QuEChERS, который позволяет выполнить эти условия. Фталаты извлекали из матрицы образца ацетонитрилом в нейтральной и кислой среде. ЭДТА использовали для предотвращения образования комплексов ионов металлов с аналитами. Были оптимизированы условия пробоподготовки: варьировали такие параметры, как масса навески пробы, количество высаливателя и экстрагента, природа высаливателя. Установлено, что применение 12 мг янтарной кислоты для создания кислой среды и 500 мг хлорида натрия в качестве высаливателя (вариант Б) обеспечивает оптимальное извлечение фталатов из представленных матриц.

Оиенка матричного эффректа. Присутствие мешающих компонентов в анализируемых экс- 

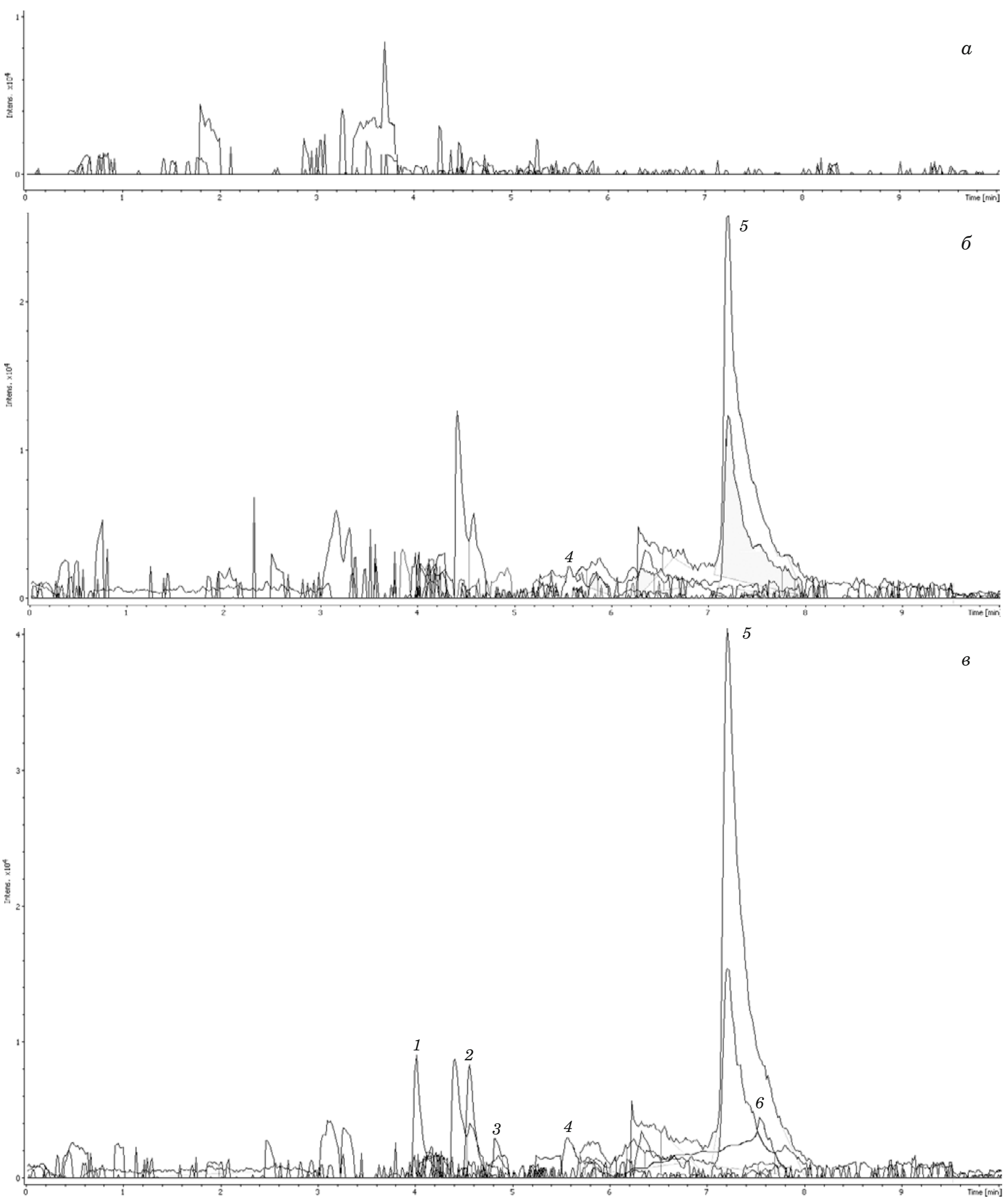

Рис. 3. Масс-хроматограммы экстрактов молока, хранившегося в стеклянной таре (a), таре из ПЭТ (б) и таре из ПЭТ с добавлением 200 нг/мл смеси фрталатов (в): 1 - диметилфталат; 2 - диэтилфталат; 3 - диаллилфталат; 4 - сумма дибутилфталата и диизобутилфталата; 5 - дииозооктилфталат; 6 - диизододецилфталат

трактах приводит к возникновению матричного эфрфекта (МЭ) - изменению интенсивности аналитического сигнала за счет подавления или усиления процесса ионизации. МЭ не учитывается при его значениях в диапазоне от -20 до $+20 \%$, от -50 до -20\% и от 20 до $50 \%$ - считается средним, а ниже $-50 \%$ или выше $50 \%$ - сильным [12]. Установлены значения МЭ для применяемых в данной работе способов приготовления образцов (пробоподготовка А и Б) (рис. 1). 
Таблица 2. Результаты определения фрталатов (нг/мл) в различных пищевых продуктах и напитках $(n=3 ; P=0,95)$

\begin{tabular}{|c|c|c|c|c|c|c|c|}
\hline \multirow[b]{2}{*}{ Аналит } & \multicolumn{7}{|c|}{ Объект исследования (количество проб) } \\
\hline & $\begin{array}{l}\text { Молоко } \\
\text { (12) }\end{array}$ & $\begin{array}{c}\text { Йогурт } \\
\text { детский (5) }\end{array}$ & $\begin{array}{l}\text { Кефир } \\
\text { (12) }\end{array}$ & $\begin{array}{l}\text { Кока-кола } \\
\text { (1) }\end{array}$ & $\begin{array}{l}\text { Вода бутили- } \\
\text { рованная (14) }\end{array}$ & $\begin{array}{l}\text { Соки } \\
(8)\end{array}$ & $s_{r}$ \\
\hline Диметилфталат & $\mathrm{H} / \mathrm{O}^{*}$ & $\mathrm{H} / \mathrm{O}$ & $\mathrm{H} / \mathrm{O}$ & $\mathrm{H} / \mathrm{O}$ & $\mathrm{H} / \mathrm{O}$ & $\mathrm{H} / \mathrm{O}$ & - \\
\hline Диэтилфрталат & $\mathrm{H} / \mathrm{o}-17,0$ & $\mathrm{H} / \mathrm{O}$ & $\mathrm{H} / \mathrm{O}$ & н/о -357 & $\mathrm{H} / \mathrm{O}$ & $\mathrm{H} / \mathrm{O}$ & $0,10-0,11$ \\
\hline Диаллилфталат & $\mathrm{H} / \mathrm{O}$ & $\mathrm{H} / \mathrm{O}$ & $\mathrm{H} / \mathrm{O}$ & $\mathrm{H} / \mathrm{O}$ & $\mathrm{H} / \mathrm{O}$ & $\mathrm{H} / \mathrm{O}$ & - \\
\hline $\begin{array}{r}\text { Сумма дибутилфрталата } \\
\text { и диизобутилфталата }\end{array}$ & $\mathrm{H} / \mathrm{o}-476$ & $\mathrm{H} / \mathrm{O}$ & H/o -259 & $\mathrm{H} / \mathrm{o}-161$ & $\mathrm{H} / \mathrm{O}$ & $\mathrm{H} / \mathrm{O}$ & $0,09-0,13$ \\
\hline Диизооктилфталат & н/o -2326 & н/о - 1961 & н/о -425 & н/о -154 & $\mathrm{H} / \mathrm{O}$ & H/o -161 & $0,12-0,15$ \\
\hline Диизододецилфталат & $\mathrm{H} / \mathrm{O}$ & $\mathrm{H} / \mathrm{O}$ & $\mathrm{H} / \mathrm{O}$ & $\mathrm{H} / \mathrm{O}$ & $\mathrm{H} / \mathrm{O}$ & $\mathrm{H} / \mathrm{O}$ & - \\
\hline
\end{tabular}

В случае пробоподготовки А сильный матричный эффект наблюдается для диметилфталата, диэтилфталата, диизобутилфталата, диизододецилфталата, его значения находятся в диапазоне от 65 до $551 \%$, для остальных фталатов наблюдается средний МЭ от 28 до $43 \%$. Использование янтарной кислоты (вариант Б) позволяет снизить матричный эффрект для положительных ионов: его значения существенно меньше и составляют $18-116 \%$. В связи с этим пробоподготовку осуществляли способом Б.

Анализ реальных проб. Исследованы пробы молока, молочной продукции, воды, соков и напитков в упаковке из ПЭТ, которые были приобретены в местных супермаркетах. Маркировка данной упаковки представлена на рис. 2.

Для решения проблемы вторичного загрязнения проб фталатами в ходе анализа использовали холостые пробы, которые не хранили в полиэтилентерефталатной упаковке. Пределы обнаружения фрталатов в воде и пищевой продукции устанавливали по соотношению сигнал/шум $=3$ (см. табл. 1), их значения значительно ниже установленных ПДК.

При определении эфиров фрталевой кислоты в воде, напитках и молочной продукции использовали способ стандартной добавки, который позволяет нивелировать матричный эффект, повысить точность определения, а также не требует устанавливать степень извлечения аналитов [13].

По разработанной методике было проанализировано более 50 образцов, в том числе, продукты детского питания. В табл. 2 представлены минимальные и максимальные значения концентраций фталатов, которые были обнаружены в напитках и продуктах питания. Установлено присутствие следующих аналитов: диизооктилфталата, дибутилфталата, диизобутилфталата и диэтилфталата. Наиболее часто в исследованных образцах присутствовал диизооктилфталат: его содержание в напитках и продуктах не нормируется, как и содержание диизобутилфрталата, поэтому сложно судить об их неблагоприятном воздействии. Наличие дибутилового эфира фрталевой кислоты в пищевой продукции не допускается (см. табл. 1). На рис. 3 приведены хроматограммы экстрактов некоторых проанализированных образцов.

Продолжительность анализа составила 20 30 мин, время определения обнаруженных аналитов - $15-30$ мин.

Таким образом, разработана методика идентификации и определения семи эфиров фрталевой кислоты в молоке, молочной продукции, соках, напитках и воде. Совместное применение способа приготовления образцов QuEChERS и метода УВЖХ - ВПМС позволило быстро и точно обнаружить целевые аналиты в продуктах питания. Использование данного варианта пробоподготовки дало возможность нивелировать матричный эффект и чувствительно определить фрталаты по точным моноизотопным массам ионов, образующихся в условиях электрораспылительной ионизации.

\section{ЛИТЕРАТУРА}

1. Zakharkiv I. B., Zui M. F., Zaitsev V. N. Dispersive Liquid-Phase Microextraction for Determination of Phthalates in Water / J. Water Chem. Technol. 2015. Vol. 37. N 2. P. $78-84$.

2. Амелин В. Г., Лаврухина О. И. Обеспечение безопасности пищевых продуктов средствами химического анализа / Журн. аналит. химии. 2017. Т. 72. № 1. С. 3 - 49.

3. Russo M. V., Avino P., Perugini L., Notardonato I. Extraction and GC-MS Analysis of Phthalate Esters in Food Matrices: a Review / RSC. Adv. 2015. Vol. 5. N 46. P. 37023 - 37043.

4. Единые санитарно-эпидемиологические и гигиенические требования к продукции (товарам), подлежащей санитарно-эпидемиологическому надзору (контролю) (утверждено решением Комиссии таможенного союза от 28. 05. 2010 г. № 299).

5. ГН 2.3.3.972-00. Предельно допустимые количества химических веществ, выделяющихся из материалов, контактирующих с пищевыми продуктами. - М.: Минздрав России, 2000. 
6. Petrovic M., Eljarrat E., Lopez de Alda M. J., Barcelo D. Analysis and environmental levels of endocrine-disrupting compounds in freshwater sediments / Trends Anal. Chem. 2001. Vol. 20. N 11. P. 637 - 648.

7. Cortazar E., Zuloaga O., Sanz J., et al. MultiSimplex optimisation of the solid-phase microextraction-gas chromatographic-mass spectrometric determination of polycyclic aromatic hydrocarbons, polychlorinated biphenyls and phthalates from water samples / J. Chromatogr. A. 2002. Vol. 978. N 1-2. P. $165-175$.

8. Farahani H., Norouzi P., Dinarvand R., Ganjali M. R. Development of dispersive liquid-liquid microextraction combined with gas chromatography-mass spectrometry as a simple, rapid and highly sensitive method for the determination of phthalate esters in water samples / J. Chromatogr. A. 2007. Vol. 172. N 2. P. $105-112$.

9. Li X., Zhong M., Xu S., Sun C. Determination of phthalates in water samples using polyaniline-based solid-phase microextraction coupled with gas chromatography / J. Chromatogr. A. 2006. Vol. 1135. N 1. P. $101-108$.

10. Yin P., Liu X., Chen H., et al. Determination of 16 phthalate esters in tea samples using a modified QuEChERS sample preparation method combined with GC-MS/MS / Food Addit. Contam. A. 2014. Vol. 31. N 8. P. 1406 - 1413.

11. Крылов В. А., Волкова В. В. Определение о-фталатов в воде с хромато-масс-спектрометрическим детектированием и концентрированием с ультразвуковым диспергированием экстрагента / Вест. ННГУ. 2014. Т. 1. № 1. С. 119 - 125.

12. Ma Y., Hashi Y., Ji F., Lin J. M. Determination of phthalates in fruit jellies by dispersive SPE coupled with HPLC-MS / J. Sep. Sci. 2010. Vol. 33. N 2. P. $251-257$.

13. López-Roldán P., López de Alda M. J., Barceló D. Simultaneous determination of selected endocrine disrupters (pesticides, phenols and phthalates) in water by in-field solid-phase extraction (SPE) using the prototype PROFEXS followed by on-line SPE (PROSPEKT) and analysis by liquid chromatography-atmospheric pressure chemical ionisation-mass spectrometry / Anal. Bioanal. Chem. 2004. Vol. 378. N 3. P. $599-609$.

14. Ferrer C., Lozano A., Aguera A., et al. Overcoming matrix effects using the dilution approach in multiresidue methods for fruits and vegetables / J. Chromatogr. A. 2011. Vol. 1218. N 42. P. $7634-7639$

15. Amelin V., Korotkov A. A simple sample preparation for simultaneous determination of chloramphenicol and its succinate esters in food products using high performance liquid chromatography/higher solution mass spectrometry / Food Addit. Contam. A. 2017. Vol. 34. N 2. P. 211 - 217.

\section{REFERENCES}

1. Zakharkiv I. B., Zui M. F., Zaitsev V. N. Dispersive LiquidPhase Microextraction for Determination of Phthalates in Water / J. Water Chem. Technol. 2015. Vol. 37. N 2. P. $78-84$.

2. Amelin V. G., Lavrukhina O. I. Food safety assurance using methods of chemical analysis / J. Anal. Chem. 2017. Vol. 72. N 1. P. $1-46$.
3. Russo M. V., Avino P., Perugini L., Notardonato I. Extraction and GC-MS Analysis of Phthalate Esters in Food Matrices: a Review / RSC. Adv. 2015. Vol. 5. N 46. P. 37023 - 37043.

4. Uniform sanitary and epidemiological requirements for products (goods) subject to control (approved by decision of Customs Union Commission May 28, 2010 N 299) [in Russian].

5. Hygienic requlations GN 2.3.3.972-00. Maximum permissible amounts of chemical substances released from materials in contact with food products. - Moscow: Health Ministry of Russia, 2000 [in Russian].

6. Petrovic M., Eljarrat E., Lopez de Alda M. J., Barcelo D. Analysis and environmental levels of endocrine-disrupting compounds in freshwater sediments / Trends Anal. Chem. 2001. Vol. 20. N 11. P. $637-648$.

7. Cortazar E., Zuloaga O., Sanz J., et al. MultiSimplex optimisation of the solid-phase microextraction-gas chromatographic-mass spectrometric determination of polycyclic aromatic hydrocarbons, polychlorinated biphenyls and phthalates from water samples / J. Chromatogr. A. 2002. Vol. 978. N $1-2$. P. $165-175$.

8. Farahani H., Norouzi P., Dinarvand R., Ganjali M. R. Development of dispersive liquid-liquid microextraction combined with gas chromatography-mass spectrometry as a simple, rapid and highly sensitive method for the determination of phthalate esters in water samples / J. Chromatogr. A. 2007. Vol. 172. N 2. P. $105-112$.

9. Li X., Zhong M., Xu S., Sun C. Determination of phthalates in water samples using polyaniline-based solid-phase microextraction coupled with gas chromatography / J. Chromatogr. A. 2006. Vol. 1135. N 1. P. $101-108$

10. Yin P., Liu X., Chen H., et al. Determination of 16 phthalate esters in tea samples using a modified QuEChERS sample preparation method combined with GC-MS/MS / Food Addit. Contam. A. 2014. Vol. 31. N 8. P. 1406 - 1413.

11. Krylov V. A., Volkova V. V. Determination of o-phthalates in water by chromatography-mass spectrometry and microextraction concentration with ultrasonic dispersion of extraction solvent / Vestnik NNGU. 2014. Vol. 1. N 1. P. 119 - 125 [in Russian].

12. Ma Y., Hashi Y., Ji F., Lin J. M. Determination of phthalates in fruit jellies by dispersive SPE coupled with HPLC-MS / J. Sep. Sci. 2010. Vol. 33. N 2. P. 251 - 257.

13. López-Roldán P., López de Alda M. J., Barceló D. Simultaneous determination of selected endocrine disrupters (pesticides, phenols and phthalates) in water by in-field solid-phase extraction (SPE) using the prototype PROFEXS followed by on-line SPE (PROSPEKT) and analysis by liquid chromatography-atmospheric pressure chemical ionisation-mass spectrometry / Anal. Bioanal. Chem. 2004. Vol. 378. N 3. P. 599 - 609.

14. Ferrer C., Lozano A., Aguera A., et al. Overcoming matrix effects using the dilution approach in multiresidue methods for fruits and vegetables / J. Chromatogr. A. 2011. Vol. 1218. N 42. P. $7634-7639$.

15. Amelin V., Korotkov A. A simple sample preparation for simultaneous determination of chloramphenicol and its succinate esters in food products using high performance liquid chromatography/higher solution mass spectrometry / Food Addit. Contam. A. 2017. Vol. 34. N 2. P. 211 - 217. 